was thereby revived in a new form. Yet where has it led us ? To a slightly better understanding of the laws governing development, but also to obstacles which defy further progress in the present state of our knowledge. For the moment, zoologists have exhausted the subject and await the arrival of a new idea. Some even deny the validity of the organiser theory, and it is possible that much of the work that has been done may be relegated historically to one of those attractive side avenues in science which forms a pleasant rendezvous for a while but is destined to be neglected later because it leads nowhere.

\section{Teaching of Statistics}

Is a paper read to the Royal Statistical Society on June 20, 1939, and printed, with the ensuing diseussion, in its Journal (102, 532 ; 1939), Dr. John Wishart pointed out, among other things necessary for the progress of the subject, the urgent need for a standard treatise on its mathematical side. There are many text-books on practical statistical methods, usually restricted to one particular field of application, such as economics, business statistics, psycho$\operatorname{logy}$, or biology and medicine, in which the reader has to accept the statements without proof. If a mathematical student asks where these proofs may be found, he may be told "You must look up the original papers, which you will not be able to understand". It is urgently necessary that a text-book should be produced to end this unsatisfactory state of affairs.

Dr. Wishart discussed in some detail what such a text-book should contain, and feared that it was beyond the powers of any one man to produce; he favoured a co-operative venture. However, many will differ from Dr. Wishart on this point, and prefer the incompleteness which may be found in the work of a single writer to the lack of unity characteristic of a book produced by a committee. In the interests of science it is desirable that we should not have to wait indefinitely until the ideal treatise can be produced. Let someone have the courage to make the attempt now ; there is no one better qualified for the task than Dr. Wishart himself.

\section{Meteorology in Southern Rhodesia}

THE meteorological report of the Department of Agriculture, Southern Rhodesia, for the year ended June 30, 1938, covers the period during which the Northern Rhodesia Weather Service was taken over from the British East Africa Meteorological Service by arrangement with the Governments concerned. After the transfer, the establishment of a new air route in Northern Rhodesia was announced by the Government of that country to replace the existing route via Broken Hill and Mpika, and this led to the setting up of a first-order meteorological station at Lusaka, while arrangements were made to open another at Kasama later. Civil aviation developed to twice its initial volume during the period in Southern Rhodesia, and the Service found it difficult to meet the increased demands for weather reports.
The formula used for the previous ten years for forecasting the seasonal rainfall gave a prediction of abundant rainfall for 1938-39, with a result that could not of course be indicated at the time of completion of this report. The only previous comparable prediction of abundant rainfall was for 1934-35, and was the most conspicuous of only three failures out of the previous nine predictions to forecast whether the rainfall would be above or below the average. On one of these three occasions the predicted and actual departures were so small that it can reasonably be regarded as a successful forecast, making the successes nearly eighty per cent, which is a very satisfactory result. It is stated that the predictions have proved of value, as may easily be credited in view of this high percentage. The report, as usual, includes extensive meteorological tables for a large number of stations for the year, among them those giving hourly values of several items for Salisbury Observatory.

\section{Mistletoe, Magic and Medicine}

THE October issue of the Bulletin of the History of Medicine contains an excellent survey by Dr. Leo Kanner, of Baltimore, of the history of mistletoe from the earliest times until the present day. The magic virtues formerly attributed to it were as follows: it was regarded as a promoter of grain and fruit harvests ; a fattener of live-stocks ; an incentive to milk production; a safeguard against ghosts and witches, nightmares and conflagrations ; a bringer of luck to farmers, home owners, hunters, warriors, wrestlers and travellers ; an agent which forces spirits to reveal their secrets; a discoverer of buried treasures, and a feeder of the mystic mandrake. It was also characteristic of its magic powers that mistletoe was regarded as a panacea, as it was used for the prevention and cure of plague, leprosy, fevers, syphilis, consumption, hæmorrhages, diseases of the heart and lungs, intestinal disorders, poór appetite, skin affections, nervous troubles and, most of all, epilepsy.

On the other hand, mistletoe was sometimes regarded as a baleful plant and was supposed to possess poisonous properties for which numerous remedies were prescribed by Galen and others. In the first half of the nineteenth century all the therapeutic properties of the mistletoe had become discredited, and it was not until 1906 that it became permanently established as a useful drug for the treatment of hypertension and later as a diuretic and styptic.

\section{Tests of a 4,000 kw. Gas-Turbine Set}

Prof. A. Stopora, in Engineering of January 5, gives a description and test results of a $4,000 \mathrm{kw}$. combustion-turbine generating set, recently constructed by Messrs. Brown, Boveri and Co., Ltd., of Baden, Switzerland, for the city of Neuchâtel. The set was built for installing in a bomb-proof chamber for use in emergencies, and consists of an axial-type air-compressor, a combustion chamber, a 